\title{
Implementation of the person-oriented approach in training in the University of Civil Engineering as a way of forming of the successful professional
}

\author{
Elena Portnyagina ${ }^{1, *}$ \\ ${ }^{1}$ Moscow State University of Civil Engineering, Yaroslavskoeshosse, 26, Moscow,129337, Russia
}

\begin{abstract}
The creation of an independent, active, self-fulfilling and thinking professional is an important problem of modern education. In the article we consider the issue of implementation of the person-oriented approach in the psychological and other humanitarian courses in the University of Civil Engineering. Much attention is given to the selfdetermination theory ofE. Desi and R. Ryan, and transactional analysis of E. Berne. The article includes the research of dominative ego states of bachelor degree students of the Institute of Construction and Architecture (ICA) of the Moscow University of Civil Engineering (MGSU). These ego states are considered as the prerequisites of readiness of adoption of independent decisions, acceptances on responsibility for the training. Based on the works of E. Desi, E. Berne, andM.Boekaerts the author has made the practical recommendations for the creation of an independent personality and the establishing of a student as a subject of study.
\end{abstract}

\section{Introduction}

Today there is a discrepancy of university graduates to requirements of the professional environment and the labor market, including such hi-tech areas as the construction [1].

There is a request in the society to the preparation of a viable and self-fulfilling professional identity of a professional who is able to adapt to changing realities quickly and to learn all lifelong.

The modern professionals have to be not only well trained and knowing the business, but first of all, they have to be active, independent, ready to study for the whole life, and realize the personal qualities and potential $[2,3]$.

As the response to this request, there is a transition from traditional training to personoriented approach in the contemporary education system. In traditional training approach, the teacher is the main source of knowledge who imparts this knowledge to a student. This approach is focused on memorizing of information and building the system of knowledge and skills. The person-oriented approach means that a student cannot only receive

"Corresponding author: elenaportnyagina@gmail.com 
knowledge from the outside, but also creates knowledge himself or herself. Thus a student is not the object of influence of a teacher, but the full-fledged subject having the own experience and capable to design knowledge, skills and abilities during the own activity. There are several definitions and concepts of the person-oriented approach in training. Such scientists have analyzed this issue as V.V.Serikov, S.V.Belova, E.V.Bondarevskaya, N.A.Alekseev, I.S.Yakimanskaya and others[4]. Based on the works of V. V. Serikov and I. S. Yakimanskaya, person-oriented approach to training and education can be defined as training which is creating the conditions for full disclosure and development of a student's personality through an independent and meaningful activities for him or her $[5,6]$.

Thus on the one hand, the person-oriented approach is based on the individual characteristics of students, on their previous experience, on the purposes and values, and on the other hand, it developes the identity of students [7].

The final transition to person-oriented approach has not come from traditional training yet. There is the question rises if students themselves are ready to change an object's position to the full-fledged subject of training?

The subject is a carrier of the activity and a source of knowledge, which means that it has a set of mental characteristics that allows to carry out an independent goal-setting, and to has initiated their own actions and behavior in general.

To answer this question we have conducted a research with the purpose to find out the autonomy and readiness of students in the making of independent decisions.

In this research we have been guided by theory of transactional analysis. In this theory Eric Berne uses a concept of the autonomy personality [8]. To achieve the autonomy it is necessary to realize three capacities such as awareness, spontaneity and intimacy. Also there is the idea of ego state in the transactional analysis. Each person has a certain set of behavioral patterns that corresponds to a particular state of his or her consciousness. I. Stewart and V. Joinesdefine ego state as the certain pattern of feelings and experience which is directly connected to a certain pattern of behavior. In the particular moment only one of three ego states, which are the Parent, the Adult or the Child, is possible. The Adult ego-state is responsible for the analysis of environmental information and adoption of objective decisions. Only being in the Adult position the person contacts the reality, and capable to analyze current situation and react responsibly. In our opinion the strong Adult is a prerequisite of formation of a student as the subject of training. If the Parent ego state dominates then the person is rather inclined to conservatism and inertness. He or she analyzes information selectively, only which confirms his or her attitudes and ideas. He or she uses thoughts, feelings and behavior typical for his or her parents and other significant adults. He or she is well-versed in standard situations, but his or her behavior is stereotypical. If the person reacts from the Child's ego, state it says that he or she is not in touch with the reality. His or her reactions are based on the previous experience and on the way he or she responded already at least once. Perhaps in the past this behavior was effective, however, in the present moment the situation could change and demand an absolutely different strategy.

In our opinion the developed Adult ego state is the basis for the development of the autonomy personality and for creation of the subject of training. Autonomy involves the ability to solve various problems, using all resources of the adult personality, to estimate real events and received information, to compare them with the recent experience and theoretical knowledge and to plan a new activity [9].These qualities are the most demanded on the labor market today.

Thus we have decided to test how developed is the Adult ego state of the students of the chosen bachelor programme.

\section{Materials and methods}


The research was conducted on the students of the bachelor degree of Institute of Construction and Architecture (ICA) of the MGSUin 2016. 48 people aged 17-18 years old have participated in the research. The Questionnaire of structural ego states has been taken as the diagnostic tool (from book Julie Hay TA for trainers in V.E.Gusakovsky's adaptations). The questionnaire consists of 21 statements. Each statement had to be rated on a scale from 0 to 3 points (from "wrong" to "absolutely right").

\section{Results}

The results of this research are presented in Figure 1.

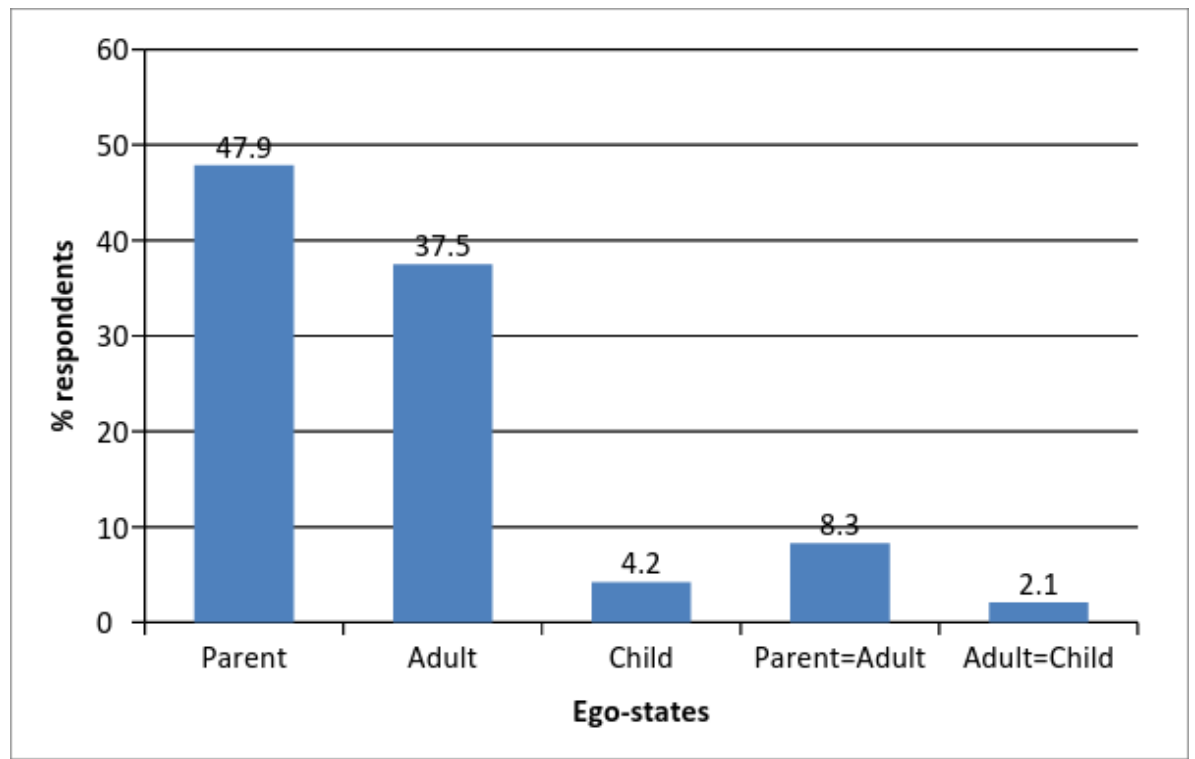

Fig.1. Ego state of participated students.

Our research have shown that $47.9 \%$ of respondents have the Parent as a dominative ego state, $37.5 \%$ - the Adult, and $4.2 \%$ - the Child. $8.3 \%$ of students have the same level of the Parent and the Adult ego states, and $2.1 \%$ have equally expressed the Adult and the Child ego states.

Thus almost a half of the respondents tend to think and act as their parents. It is possible to assume that they are not inclined to argue and build their own opinion, but they prefer to use well-established opinions and points of view. The Parent is rigid and less adaptable. The dominative Parental ego state might cause narrow frame and stereotypical thinking, based on prejudices and biased opinions, also people with the dominative Parent ego state might have negative attitude to innovations and be too conservative. About $40 \%$ of respondents, on the contrary, analyze a situation. They are in contact with reality, they form an own point of view by analyzing current circumstances and available information. The position of the Adult allows flexibility in decision-making, forming a responsible position and fast reacting to the changing events. The Adult is the most rational ego state. The person with the strong Adult ego state interacts leaning on the present, considering information from the past. Such person is independent, competent and realistic. 4,2\% of respondents have the dominative Child ego state. It describes them as people tend to react in the usual way, socially approved, as they have learned previously, though their behavior often is not corresponding to the particular situation. They often behave infantile and 
conformal[10].

\section{Discussion}

Analyzing the results of this research we conclude that nearly $50 \%$ of respondents are inclined to prove as object of influence in training. It is not surprising because this position was supported by traditional approach in training for a long time. Therefore, they need to make further efforts to develop the awareness, independence, responsibility, flexibility in decision-making and thus become competitive professionals [11].

What could force them to refuse an object position? Could a teacher at the university somehow affect that? How is it possible to promote a development of an autonomy personality?

The theory of self-determination of E. Desiand R. Ryan is the most successful and applicable in system education, in our opinion. They studied human motivation, development, and wellness. Particular attention they paid to intrinsic and extrinsic motivation. External motivation is not associated with the content of the activity itself and the satisfaction from doing so. It does not contribute personal wellness. Authors say that the extrinsic motivation, especially in its widespread option of "carrot and stick" (an award and punishment), is the least effective because it suppresses intrinsic motivation. Each person has an internal motivation that relies on cognitive activity and interest.

One of the main ideas of this approach is the idea of three basic requirements which are the cornerstone of intrinsic motivation: autonomy, competence and relatedness need.

The need for autonomy means aspiration of the person to initiate own actions, to control the behavior and to define the purposes. The need for competence is expressed in desire to achieve certain results, to feel the awareness, to be a professional in the particular area. The relatedness need means the aspiration to establish the reliable and confidential relations with others, to feel the accessory. The internal motivation is formed as a result of requirements satisfaction in competence and autonomy [12].Thus supporting intrinsic motivation we increase an efficiency of activity and psychological wellbeing of a person. The idea of three basic requirements is crossed with E. Berne's idea about the autonomy personality and its components. It is necessary to support the students' desire to achieve results and to connect their personal purposes to the purposes of training and education. By that we will increase their awareness of the training process and will develop an autonomy personality. The most appropriate environment for realization of the person-oriented approach and development of the autonomy personality in the University of Civil Engineering, in our opinion, is psychological and in general humanitarian disciplines. Training format, content, and the most importantly, education and attitudes of teachers allow to change students' attitude toward training in general, to form an active position to their education, to create intrinsic motivation [13]. This might allow to form an autonomy personality with the strong Adult ego state that will ensure the competitiveness of graduates. Having analyzed the works of E.Desi and R.Ryan, I. S. Yakimanskaya, M.Boekaerts, E. Berne and other authors, we have formulated some recommendations about realization of the person-oriented approach in education and to formation of the student as subject of training:

1. To stimulate intrinsic motivation, relying on cognitive activity. It could be done through connection of personal interests of students with educational and professional activity. It should be based on the personal goals and values of students, finding points of intersection of their personal interests with the education.

2. To create conditions where a student can be the initiator of the own actions. Strengthening of extrinsic motivation causes the weakening of intrinsic. When a student 
feels that his or her actions are controlled by a teacher, his or her need for autonomy is frustrated.

3. To form feeling of the own competence. To give positive feedback when the student has successfully completed the task of optimal level. Thus the need to be effective and to achieve internal and external results is maintained.

4. To maintain the desire for affiliation by team building activities. To create the atmosphere of the reliable relations both between students, and their teachers.

5. To maintain interest and pleasure from educational activity. To give the chance to choose a type of activity in the class. This can be done by offering different types of tasks and exercises.

6. It is important to take into the account the psychological types of students, to assist them in setting of their own goals. To correct them if necessary, to reveal the most relevant and achievable in the educational process.

7. To consider ideas of students about the effort they put into the task. To form the belief that success depends not on innate abilities, but on their effort and willpower.

8. To keep a mentoring and an affiliate position in relation to students. To carry out an adequate form of control, to take care of them.

Of course, this list of recommendations is incomplete. The person-oriented approach, self-determination theory, transactional analysis and the idea of self-regulation leaning have much more tools and opportunities for the formation of the autonomy person than have been described in this article. The problem of this research is so broad and actual so we plan to continue our study.

\section{Conclusions}

This research is preliminary. In the research an attempt has been made to find out how teaching at the university could contribute to the creation of graduates that meet the requirements of the modern labor market. The received results allow to draw a number of primary conclusions:

1. The person-oriented approach in training allows to prepare competitive professionals by development of the respective qualities.

2. The majority of students is not ready to transition to the person-oriented approach.

3. Practical application of the self-determination theory, transactional analysis and the concept of self-regulation leaning allow students to develop the activity, awareness, flexibility in decision-making and thereby increase their competitiveness.

4. The format of training, approach to teaching and education of the humanities lecturers are the most suitable environment for the formation of an autonomy and self-actualizing personality in the University of Civil Engineering.

5. Practical recommendations for implementation of the personal oriented approach in training have been made.

Summing up the research results, it is possible to draw the conclusion that creation of a capability to make independent decisions, to set own purposes and to plan the own activities by students, is a difficult, but significant task that all of the teachers face. It is necessary to remember that professional and personal establishing of the student depends on a contribution and the personality of a teacher.

\section{References}

1. I.Pryadko,International Journal of Applied Engineering Research 21,42147-42152 (2015) 
2. A. Ishkov,Procedia - Social and Behavioral Sciences 142, 54-58 (2014)

3. E. Khripko, Matec web of conferences 73, 07021 (2016)

4. S. Gulyants, Herald CSPU 2, 40-52 (2009)

5. I.Yakimanskaya, Person-Oriented Training Model Construction, 7 (2001)

6. V.Serikov, Theory and Designing Practice, 93 (1999)

7. E. Shnyrenkov, I. Pryadko, Procedia Engineering 117, 325-330 (2015)

8. E.Berne, The Psychology of Human Destiny, 14(2005)

9. I. Stewart, V. Joines, Socio-Psychological Center,43 (1996)

10. D.I. Shustov, Guidelines for clinical transactional analysis, 12(2009)

11. A.Ishkov, N.Miloradova, A.Chernyshev, Procedia - Social and Behavioral Sciences 171, 765-770 (2015)

12. R.Ryan, E. Deci, Contemporary Educational Psychology 25, 54-67(2000)

13. E. Shnyrenkov, E. Romanova, Procedia Engineering 117, 336-341 (2015) 